\title{
Flame retardancy of wood-plastic composites by radiation-curing phosphorus-containing resins
}

\author{
Maximilien Gibier ${ }^{\mathrm{a}}$, Clement Lacoste ${ }^{\mathrm{a}}$, Stephane Corn ${ }^{\mathrm{a}}$, Monica Francesca Pucci ${ }^{\mathrm{a}}$, \\ Quoc Khoï Tran ${ }^{\mathrm{b}}$, Laia Haurie ${ }^{\mathrm{c}}$, Rodolphe Sonnier ${ }^{\mathrm{a}, *}$ \\ ${ }^{\text {a } C e n t r e ~ d e s ~ M a t e ́ r i a u x ~ d e s ~ M i n e s ~ d ' A l e ̀ s ~(C 2 M A), ~ 6, ~ A v e n u e ~ d e ~ C l a v i e ̀ r e s, ~ 30319, ~ A l e ̀ s ~ C e d e x, ~ F r a n c e ~}$ \\ ${ }^{\mathrm{b}}$ ARC-Nucléart, CEA-Grenoble, 17 Avenue des Martyrs, 38054, Grenoble, France \\ ${ }^{\mathrm{c}}$ Universitat Politècnica de Catalunya, Barcelona School of Building Construction, Av. Doctor Marañon 44, 08028, Barcelona, Spain
}

\begin{abstract}
A B S T R A C T
Wood-plastic composites were prepared by impregnating softwood and tropical hardwood by a radiation-curing resin containing phosphorus or chlorine groups as flame retardant. Microscopic observations revealed that the heterogeneous impregnation depends on the density but also on the wood species and sample orientation. Physical properties (hardness, stiffness, conductivity, water content) of the unmodified woods and their resinimpregnated counterparts were examined and correlated with their densities. The flame retardancy was investigated by cone calorimeter tests. Although the incorporation of the resin is detrimental to the flame retardancy, the addition of phosphorus or chlorine groups allows a decrease in flammability. Phosphorus-containing resins limit the smoke release in comparison to chlorine-containing resin. Finally, the denser woodplastic composites exhibit improved mechanical properties without increasing the flammability in comparison with their unmodified wood counterparts.
\end{abstract}

\section{Keywords:}

Wood flammability

Radiation-curing

Phosphorus flame retardants

\section{Introduction}

Wood-based materials are widely used for various applications requesting flame retardant properties as cladding or decking board. Wood burns quite slowly, leaves gases, tar and char and releases less energy (heat of combustion is around 10-12 kJ/g) than many synthetic polymers. Nevertheless it needs flame retardant treatments to meet construction requirements, especially for higher and larger buildings for example. Wood is also the only combustible material used for structural applications. The use of timber in larger structures relies on fire engineering design to ensure that the building can retain its structural integrity for sufficient time. In Europe, the fire resistance of wood-based structural elements is described by Eurocode 5-1.2 based on the reduced cross section method with a special attention dedicated to the charring rate (1995-1-2 and Eurocode, 2005), which depends on the wood species (hardwood or softwood) and its density (Njankouo et al., 2004, 2005). The timber density is considered as the most important parameter to predict the combustion rate (Haurie et al., 2019). However, other parameters like the water content, the sample orientation (Momoh et al., 1996), and the chemical components (Shebani et al., 2008) can also affect the wood fire behavior.

Flammability of wood has already been extensively studied as well as the flame retardancy strategies. A recent overview from Lowden and Hull lists the main approaches (Lowden and Hull, 2013). Phosphorus flame retardants are nowadays the main alternative to halogenated compounds to impart flame retardancy to materials including oil-based polymers but also ligno-cellulosic resources as wood. Phosphorus additive flame retardants can be used but present some important drawbacks. They increase the water content of wood promoting fungal decay. Moreover, organophosphorus flame retardants have usually high volatility while inorganic (poly)phosphates are often soluble in water and can be easily leached when used in outdoor applications. Therefore flame retardancy properties can be negatively impacted during ageing. These drawbacks are not specific to wood and have been already identified when phosphorus flame retardants are used in polymers (Mangin et al., 2018; Jimenez et al., 2013). It is believed that the covalent grafting of phosphorus compounds to the macromolecular structure limits their volatility and their migration during ageing.

A method to modify the properties of wood and to develop woodplastic composites is to impregnate wood by a resin which is then radiation-cured. This method was proposed in the sixties (Munnikendam, 1967) and was also used to consolidate waterlogged wood in the context of cultural heritage conservation (Tran et al., 1990). Although cellulose is very sensitive to ionizing radiations (Le Moigne et al.,

\footnotetext{
* Corresponding author.

E-mail address: rodolphe.sonnier@mines-ales.fr (R. Sonnier).
} 
2017), the doses needed to cure acrylate or styrenic resins (typically several dozens of $\mathrm{kGy}$ ) are too low to degrade wood structure. Boryziak has shown that the content of cellulose in Scotch pine wood submitted to radiation does not decrease for doses lower than $300 \mathrm{kGy}$ (Boryziak, 2010).

As resins are usually much more flammable than wood, such woodplastic composites exhibit high flammability. Nevertheless, impregnating wood with a thermoset resin incorporating flame retardants covalently grafted to the network may limit the flammability and solve the drawbacks of phosphorus additives listed above (high volatility, migration and leaching and also hydrophilic nature because resin can fill the pores).

The objective of this article is twofold. The first one is to prepare wood-plastic composites by impregnating wood by a radiation-cured resin containing phosphorus comonomers. The influence of these comonomers on the impregnation and material properties is assessed. The second objective is to conclude about the efficiency of this method to improve the flame retardancy compared to unmodified wood itself.

\section{Materials and methods}

\subsection{Materials}

\subsubsection{UPE resins}

Unsaturated Polyester (UPE) resins used in this study were provided by Polynt Composites. The first resin (called $\mathrm{R}$ in that study) is a nonflame retarded Norsodyne 095283 UPE resin containing 30\% styrene by weight. The second resin (called $\mathrm{R}+\mathrm{Cl}$ ) is a Norsodyne $\mathrm{H} 84233 \mathrm{~L}$ UPE resin which contains about $30 \%$ styrene and about $20 \%$ chlorine. This resin has already fire retardant properties provided by chlorine which is a halogenated fire retardant. According to manufacturer, its Brookfield viscosity at $23{ }^{\circ} \mathrm{C}$ is $400-500 \mathrm{mPa}$ s.

\subsubsection{Flame retardants}

Two flame retardants have been incorporated in the Norsodyne 095283 UPE resin in order to reach $1.6 \mathrm{wt} \%$ of phosphorus in the resin. The flame retardants used were bis(2-(methacryloyloxy)ethyl) phosphate (called M1 in that study) and dimethyl vinylphosphonate (called M2) from Sigma-Aldrich in order to use flame retardants more ecofriendly than halogenated ones. The chemical structures are shown in Fig. 1.

\subsubsection{Wood species}

Samples of beech, chestnut and Corsican pine were analyzed and impregnated by different flame retardant resins in this study. Seven species of hardwood from Mexico with different appearance and density have also been included in this study. These samples were only impregnated with the non-flame retarded resin and the resin containing M1 monomer.

Two samples of each species have been impregnated for each UPE resin (with or without flame retardant). Table 1 summarizes the different wood species used in this study.

\subsection{Wood treatment procedure}

The wood-plastic composites were prepared at the ARC-Nucleart Laboratory of CEA-Grenoble. First, the flame retardant monomer was<smiles>C=C(C)C(=O)OCCOP(=O)(O)OCCOC(=O)C(=C)C</smiles><smiles></smiles>

\section{M1}

Fig. 1. Chemical structure of the phosphorus flame retardants M1 and M2.
Table 1

List of different wood species and samples features.

\begin{tabular}{|c|c|c|c|c|c|}
\hline Code & Name & $\rho\left(\mathrm{kg} / \mathrm{m}^{3}\right)$ & $\begin{array}{l}\text { Sample } \\
\text { size }(\mathrm{cm})\end{array}$ & $\begin{array}{l}\text { Sample } \\
\text { orientation }^{\mathrm{a}}\end{array}$ & Surface \\
\hline TD & $\begin{array}{l}\text { Tabebuia } \\
\text { donnell - } \\
\text { smithii }\end{array}$ & $491 \pm 11$ & $7 * 7 * 1$ & Radial & \\
\hline EC & $\begin{array}{l}\text { Enterolobium } \\
\text { cyclocarpum }\end{array}$ & $491 \pm 40$ & $7 * 7 * 1$ & Radial & \\
\hline TR & Tabebuia rosea & $579 \pm 25$ & $7 * 7 * 1$ & Radial & \\
\hline $\mathrm{SH}$ & $\begin{array}{l}\text { Swietenia } \\
\text { humilis }\end{array}$ & $645 \pm 19$ & $7 * 7 * 1$ & Radial & \\
\hline LA & $\begin{array}{l}\text { Lysiloma } \\
\text { acapulcensis }\end{array}$ & $677 \pm 21$ & $7 * 7 * 1$ & Radial & \\
\hline CA & $\begin{array}{l}\text { Cordia } \\
\text { elaeagnoides }\end{array}$ & $1093 \pm 38$ & $7 * 7 * 1$ & Radial & \\
\hline TC & $\begin{array}{l}\text { Tabebuia } \\
\text { Chysantha }\end{array}$ & $1180 \pm 19$ & $7 * 7 * 1$ & Radial & \\
\hline $\mathrm{HE}$ & $\begin{array}{l}\text { Beech } \\
\text { Fagus sylvatica }\end{array}$ & $711 \pm 35$ & $7 * 7 * 1$ & Radial & \\
\hline $\mathrm{C}$ & $\begin{array}{l}\text { Chestnut } \\
\text { Castanea }\end{array}$ & $529 \pm 32$ & $10 * 10 * 2$ & Transverse & \\
\hline $\mathrm{P}$ & $\begin{array}{l}\text { Corsican pine } \\
\text { Pinus nigra } \\
\text { subsp. laricio }\end{array}$ & $500 \pm 8$ & $10 * 10 * 2$ & Transverse & \\
\hline PR & $\begin{array}{l}\text { Pine Laricio } \\
\text { Corsican } \\
\text { Pinus nigra } \\
\text { subsp. laricio }\end{array}$ & $480 \pm 27$ & $10 * 10 * 2$ & Radial & \\
\hline
\end{tabular}

a Orientation of the surface exposed to cone calorimeter.

added to the UPE resin and the mixture was homogenized. The resin was heated around $30{ }^{\circ} \mathrm{C}$ for $10 \mathrm{~min}$ to reduce its viscosity and to enhance the impregnation process.

The samples of wood were impregnated with resin by a vacuum/ pressure process (Tran et al., 2009). First, the samples were degassed in an autoclave under vacuum for $2 \mathrm{~h}$. Then, the resin was moved into the autoclave and a nitrogen pressure of 6 bars was applied during one night (around $15 \mathrm{~h}$ ), in order to impregnate in the core of the sample. Note that the wood samples were completely submerged by the resin.

After impregnation, the samples were irradiated in the gamma irradiation room using a Cobalt 60 source. The samples received a radiation dose of 30-40 kGy at a dose rate of $1.3 \mathrm{kGy} / \mathrm{h}$.

\subsection{Characterization methods}

\subsubsection{Impregnation ratio}

The wood samples were weighed before and after modification. The impregnation ratio of resin in the samples was calculated using the following equation:

Impregnation ratio $(\%)=100^{*}\left(W_{1}-W_{0}\right) / W_{1}$

$W_{0}$ and $W_{1}$ are the weights of a wood sample before and after impregnation, respectively.

\subsubsection{FT-IR spectroscopy}

Fourier-transform infrared spectroscopy (Vertex 70, Bruker) was used to assess the radiation-curing of the resins through the extinction of the band at $1630-1650 \mathrm{~cm}^{-1}$ corresponding to the vibration of the double bond $\mathrm{C}=\mathrm{C}$.

\subsubsection{Differential scanning calorimetry (DSC)}

The PYRIS Diamond DSC (PerkinElmer) was used to determine the 
glass transition temperature of the cross-linked resins. About $10 \mathrm{mg}$ specimen was put in a perforated aluminum crucible. Specimen was heated from 0 to $150{ }^{\circ} \mathrm{C}$ at a heating rate of $20^{\circ} \mathrm{C} / \mathrm{min}$.

\subsubsection{Thermogravimetric analyses (TGA)}

Thermogravimetric curves were recorded with a SETSYS Evolution (SETARAM Instrumentation) from $20{ }^{\circ} \mathrm{C}$ to $900{ }^{\circ} \mathrm{C}$ at the scan rate of $1{ }^{\circ} \mathrm{C} / \mathrm{min}$ under a nitrogen atmosphere. Crosslinked resins and samples of beech, pine and chestnut were analyzed.

\subsubsection{PCFC analyses}

The pyrolysis combustion flow calorimeter (PCFC - Fire Testing Technologies) was used to determine the flammability characteristics of cured resins. About $3 \mathrm{mg}$ of each specimen was pyrolyzed in a chamber from $100{ }^{\circ} \mathrm{C}$ to $750{ }^{\circ} \mathrm{C}$ at $1{ }^{\circ} \mathrm{C} / \mathrm{s}$ under a nitrogen flow $\left(100 \mathrm{~cm}^{3} / \mathrm{min}\right)$. The evolved gases were transported to the combustor that works at $900{ }^{\circ} \mathrm{C}$ in a flow of nitrogen $\left(80 \mathrm{~cm}^{3} / \mathrm{min}\right)$ and oxygen $\left(20 \mathrm{~cm}^{3} / \mathrm{min}\right)$. Combustion is complete in these conditions. Heat release rate is calculated from oxygen depletion (Huggett relation).

\subsubsection{Scanning electron microscopy (SEM)}

The morphology of the samples was studied by scanning electron microscopy using an ESEM FEI Quanta 200 FEG. Elemental analysis using Energy Dispersive X-Ray Spectroscopy (EDS - Oxford Instruments) was performed to map phosphorus and chlorine in the samples. The surface of the samples was polished with fine abrasive discs.

\subsubsection{Atomic force microscopy (AFM)}

Samples were also studied with a MFP3D atomic force microscope (AFM) from Oxford-Asylum. An ultramicrotome (UMEC7 from Leica) equipped with Diatome diamond knives was used to prepare the surface of the samples. AFM maps $\left(55 \times 55 \mu^{2}\right)$ of the samples topography and elastic modulus were performed at a scan rate of $0.2 \mathrm{~Hz}$ with a silicon probe (AC160TS-R3 from Asylum) in bimodal tapping mode (Amplitude Modulation - Frequency Modulation mode).

\subsubsection{Thermal conductivity}

The thermal conductivity of the samples was determined by a hot wire conductivity-meter FP2C (NeoTIM). The probe is placed between 2 samples. It produces a local warm-up and measures the rise of temperature as a function of time. The acquisition software records the data and then calculates the thermal conductivity of the samples. The tests were performed at a power of $0.2 \mathrm{~W}$ over a sampling time of $100 \mathrm{~s}$.

\subsubsection{Humidity of woods}

The water content of the different samples was determined according to the procedures inspired from the NF B 51-004 standard. The samples were stabilized (kept) at $22{ }^{\circ} \mathrm{C}$ and $50 \%$ RH (Relative Humidity) and then dried in an oven at $103( \pm 2)^{\circ} \mathrm{C}$. The samples were weighed before and after drying. The humidity $(\mathrm{H})$ was calculated using the following equation:

$H=\frac{W_{H}-W_{0}}{W_{0}} * 100$

$W_{H}$ and $W_{0}$ are the weight of the wood at $22{ }^{\circ} \mathrm{C} / 50 \% \mathrm{RH}$ and after drying, respectively.

The volume shrinkage at the same humidity level $\left(22{ }^{\circ} \mathrm{C}\right.$ and $50 \%$ $\mathrm{RH}$ ) was also determined for the different samples (with or without resin). The shrinkage was calculated using the following equation based on NF B 51-006 standard:

$r=\frac{V-V_{0}}{V_{0}} * 100$

$V$ and $V_{0}$ are the volume of the wood at $22{ }^{\circ} \mathrm{C} / 50 \% \mathrm{RH}$ and after drying, respectively.

\subsubsection{Contact angle}

Contact angle measurements with water on wood-plastic composites were carried out using a Drop Shape Analyzer tensiometer DSA30 (Krüss). Images of sessile drops with a volume of $3 \mu$ l were captured by a camera and analyzed with the software Advance of the DSA30, allowing to determine the contact angle from the fit of the drop shape with the Laplace equation (Hoorfar and Neumann, 2006). It is important to observe that the drop shape, and then the contact angle, depends on the surface state, presenting physico-chemical heterogeneities, and particularly on the orientation of sample (Neuhaus et al., 2012). Therefore, results of contact angles were used here to evaluate, for each wood species, the effect of resin addition with or without flame retardants on the hydrophilic nature of samples. Contact angles were measured at the initial contact of water with the sample surface (at $t=$ $O s$ ). For each sample five sessile drop measurements were performed.

\subsubsection{Shore D hardness}

The Shore D hardness test was measured with a Shore D durometer (Zwick) using a $49 \mathrm{~N}$ mass. 5 measurements were performed for each sample following NF EN ISO 868 standard and the mean value was calculated.

\subsubsection{Flexural elastic modulus from structural vibration analysis}

In order to study and compare the stiffness of the various woods and wood-plastic composites, their flexural moduli were assessed from an experimental-numerical structural vibration analysis. To measure its first natural resonant frequencies, each sample listed in Table 1 was submitted to a light mechanical impact while being monitored with a small Kistler accelerometer. The impact transient response was acquired with a National Instruments NI-USB-4431 acquisition system and the corresponding Frequency Response Function (FRF) was computed through the Fourier transform embedded in the ModalView dedicated software. Every peak exhibited by a FRF is associated to a specific natural frequency and mode shape. The Ansys finite element software allowed conducting the modal analysis of a 3D numerical model of each sample. "Free" boundary conditions were considered in the modeling, as samples were tested "suspended" with soft rubber bands. In order to proceed to its identification, the elastic modulus was set in the model so that the first computed eigenfrequency is equal to the experimental fundamental natural frequency, which corresponds to a flexural mode shape (as evidenced by the numerical modal analysis).

\subsubsection{Cone calorimeter}

Cone calorimeter (from Fire Testing Technologies) is used to study the fire behavior of bench-scale samples based on Huggett's principle. The tests were carried out according to ISO 5660 standard with samples of $70 \times 70 \times 10 \mathrm{~mm}^{3}$ and $100 \times 100 \times 20 \mathrm{~mm}^{3}$ at a distance of $25 \mathrm{~mm}$ from the cone. Heat flux was fixed at $35 \mathrm{~kW} / \mathrm{m}^{2}$. Note that some samples have already been tested (Haurie et al., 2019) but the test conditions (wrapping with foil) were not exactly the same. Therefore the HRR curves cannot be compared but the tendencies (especially the influence of density on the fire behavior of non-modified woods) are similar.

\section{Results and discussion}

\subsection{Resins characterization}

\subsubsection{Curing of resins}

The complete curing of the resin in wood-plastic composites was assessed qualitatively from the stickiness of the surface. Above $30-40 \mathrm{kGy}$, the surface is not sticky anymore. To confirm that this dose range is high enough, resins were also radiation-cured alone and FTIR analyses were carried out. Fig. 2 shows the spectra in the range $1500-1800 \mathrm{~cm}^{-1}$ for the four resins before and after curing. The band at $1630-1650 \mathrm{~cm}^{-1}$ corresponding to $\mathrm{C}=\mathrm{C}$ double bond completely 


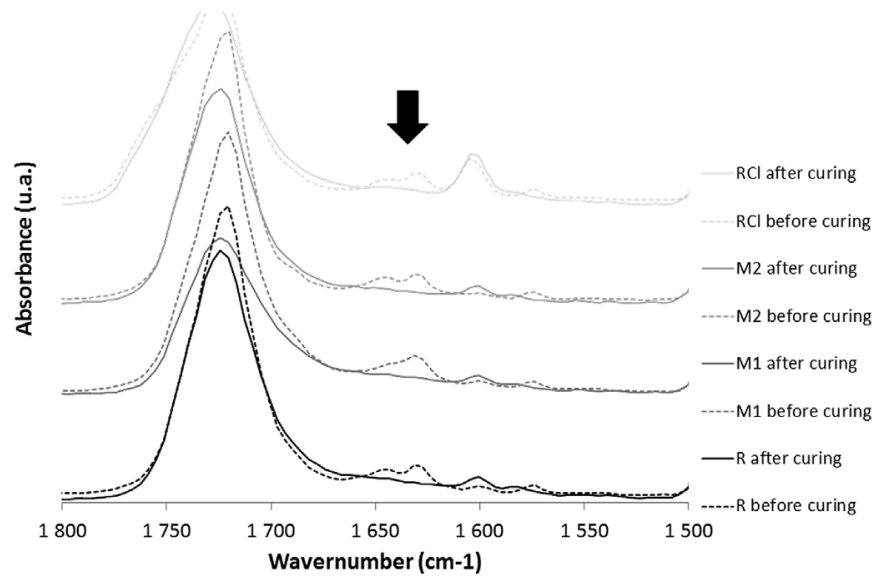

Fig. 2. FTIR spectra for resins before and after radiation curing of resins alone (black arrow shows the band at $1630-1650 \mathrm{~cm}^{-1}$ corresponding to $\mathrm{C}=\mathrm{C}$ bonds).

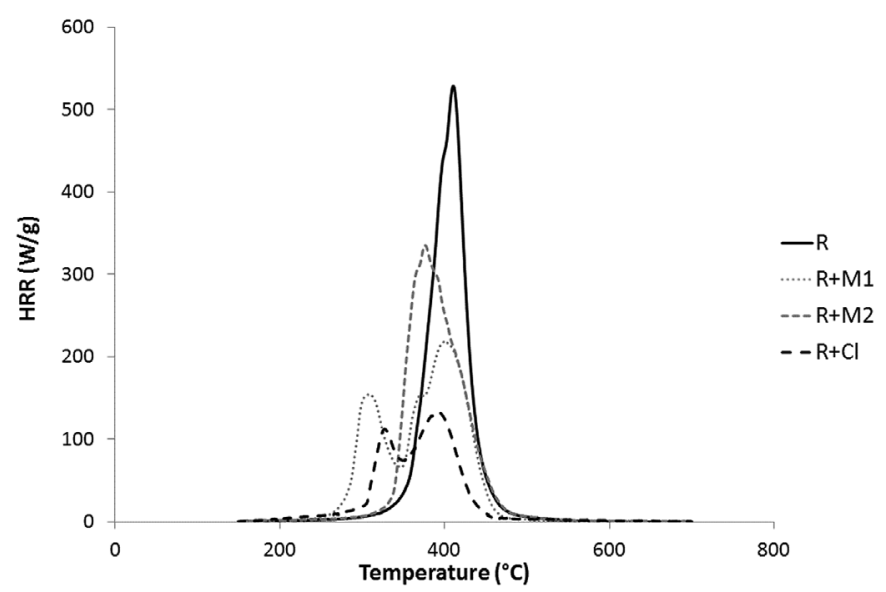

Fig. 3. Heat release rate versus temperature for studied resins from PCFC analyses.

disappears after irradiation in all cases suggesting that the complete curing is ensured. Nevertheless, it may be kept in mind that some components of the wood may affect the curing of the resin. This possibility has not been assessed in the present study.

After complete curing, glass transition temperature $\left(\mathrm{T}_{\mathrm{g}}\right)$ was measured for the four resins using differential scanning calorimetry (data not shown - resins were cured alone). The $\mathrm{T}_{\mathrm{g}}$ of the non-flame retarded resin is $65^{\circ} \mathrm{C}$. A slight decrease is observed for flame retarded resins ( $62{ }^{\circ} \mathrm{C}$ for resins containing M1 and M2 and $63^{\circ} \mathrm{C}$ for chlorinated resin).

\subsubsection{Flammability of resins}

Thermal stability and flammability of the resins were assessed at microscale using thermogravimetric analysis (TGA) and pyrolysis combustion flow calorimetry (PCFC). Heat release rate curves are shown in Fig. 3 and main results are listed in Table 2.

Non-flame retarded resin exhibits an intense peak of heat release rate (pHRR, 450-500 W/g) at around $400{ }^{\circ} \mathrm{C}$. Total heat release reaches

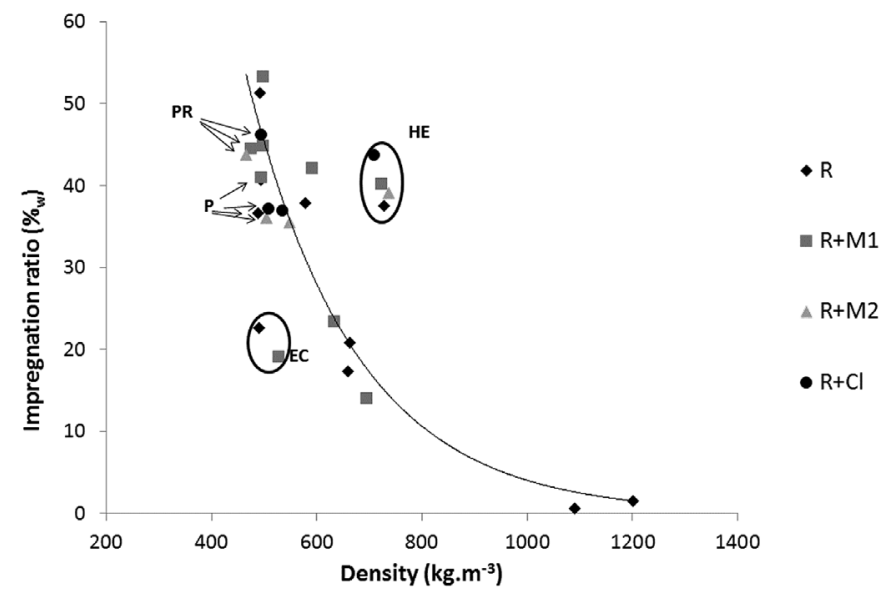

Fig. 4. Impregnation ratio versus density for all prepared samples.

$25-26 \mathrm{~kJ} / \mathrm{g}$. Its pyrolysis left almost no residue. On the contrary, the incorporation of phosphorus comonomers leads to a significant decrease in pHRR. Residue is significantly enhanced $\left(17-20 \%\right.$ at $\left.700{ }^{\circ} \mathrm{C}\right)$ but THR is only marginally reduced. Moreover, the thermal stability of phosphorus-containing resins is reduced, which is quite common when phosphorus compounds are added into polymers. Note that M1 leads to several decomposition peaks. The first one is centered at $300{ }^{\circ} \mathrm{C}$. Chlorinated resin exhibits two smaller HRR peaks (100-130 W/g) at 320 and $390{ }^{\circ} \mathrm{C}$ and a larger decrease in THR $(13 \mathrm{~kJ} / \mathrm{g}$ versus $23-26 \mathrm{~kJ} /$ $\mathrm{g}$ for other resins). Residue at $700{ }^{\circ} \mathrm{C}$ is slightly higher than $20 \%$.

To conclude, resins containing chlorine or phosphorus compounds are well flame retarded and can be correctly cured at the same radiation dose as the non-flame retarded resin.

\subsection{Impregnation process}

\subsubsection{Impregnation ratio}

Impregnation ratio was assessed and plotted versus wood density in Fig. 4. It can be observed that the impregnation ratio ranges from 2 to $54 \mathrm{wt} \%$. For most of woods, there is a clear dependency of impregnation ratio on density. Lower is the density, more porous is the wood and easier is the diffusion of the resin in the wood structure. The densest Mexican woods are non-impregnated (impregnation ratio $<3 \mathrm{wt} \%$ ). Nevertheless, two woods exhibit a different behavior. HE (beech) is easily impregnated with an impregnation ratio significantly higher than other woods having a similar density (around $40 \mathrm{wt} \%$ versus $20 \mathrm{wt} \%$ ). EC appears to be difficult to impregnate. Its impregnation ratio is only $20 \mathrm{wt} \%$ versus $35-45 \mathrm{wt} \%$ for woods having a similar density. The comparison between P and PR samples allows to highlight the influence of sample orientation. Radial orientation may lead to a slightly higher impregnation ratio but further investigations are needed to address this issue.

Finally it can be observed that there is no systematic difference in impregnation ratio between the different resins for a same wood. The impregnation ratio is mainly dependent on the wood species, the sample orientation and its density and quite independent on the resin.

Other parameters are certainly influent as the viscosity of the resin or the morphology of the wood pores. Nevertheless, these parameters

Table 2

Summary of results from TGA and PCFC analysis.

\begin{tabular}{llllll}
\hline & Temperature at 10 wt $\%$ mass loss $\left({ }^{\circ} \mathrm{C}\right)$ & pHRR $(\mathrm{W} / \mathrm{g})$ & Temperature at pHRR $\left({ }^{\circ} \mathrm{C}\right)$ & THR $(\mathrm{kJ} / \mathrm{g})$ & 25.9 \\
\hline $\mathrm{R}$ & 355 & 459 & 407 & 2.9 & 2.5 \\
$\mathrm{R}+\mathrm{M} 1$ & 289 & $152 / 220$ & $308 / 400$ & 24.9 & 17.3 \\
$\mathrm{R}+\mathrm{M} 2$ & 327 & 324 & 375 & 13.0 & 20.2 \\
$\mathrm{R}+\mathrm{Cl}$ & 312 & $103 / 134$ & $328 / 394$ & 21.8 \\
\hline
\end{tabular}



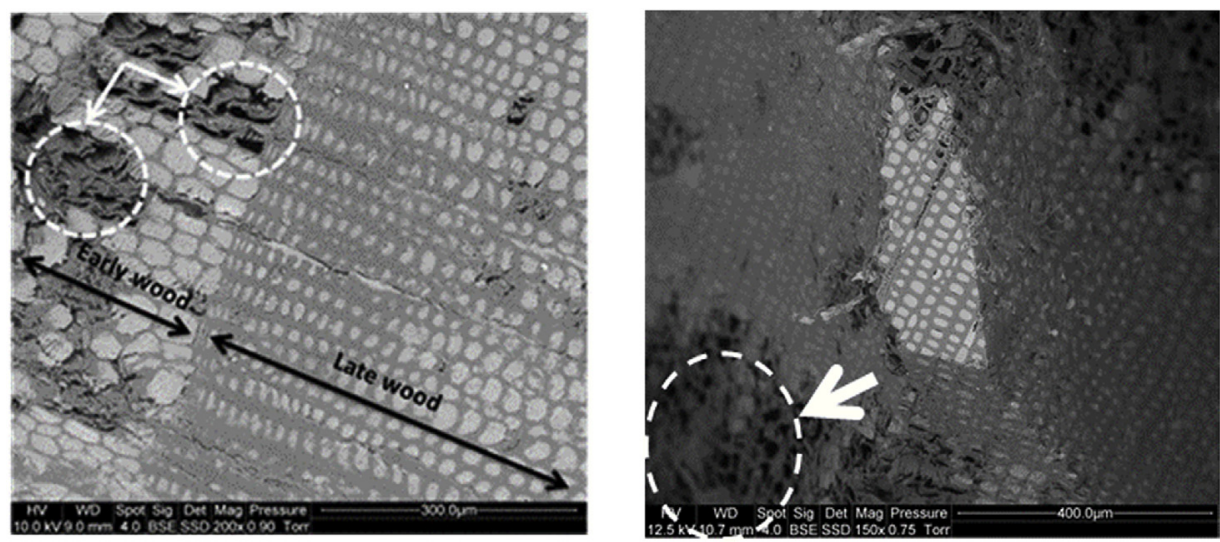

Fig. 5. SEM pictures showing pine wood impregnated by the chlorinated resin: surface (left) and at a depth of $1 \mathrm{~cm}$ (right) - The white arrow points out a nonimpregnated zone.

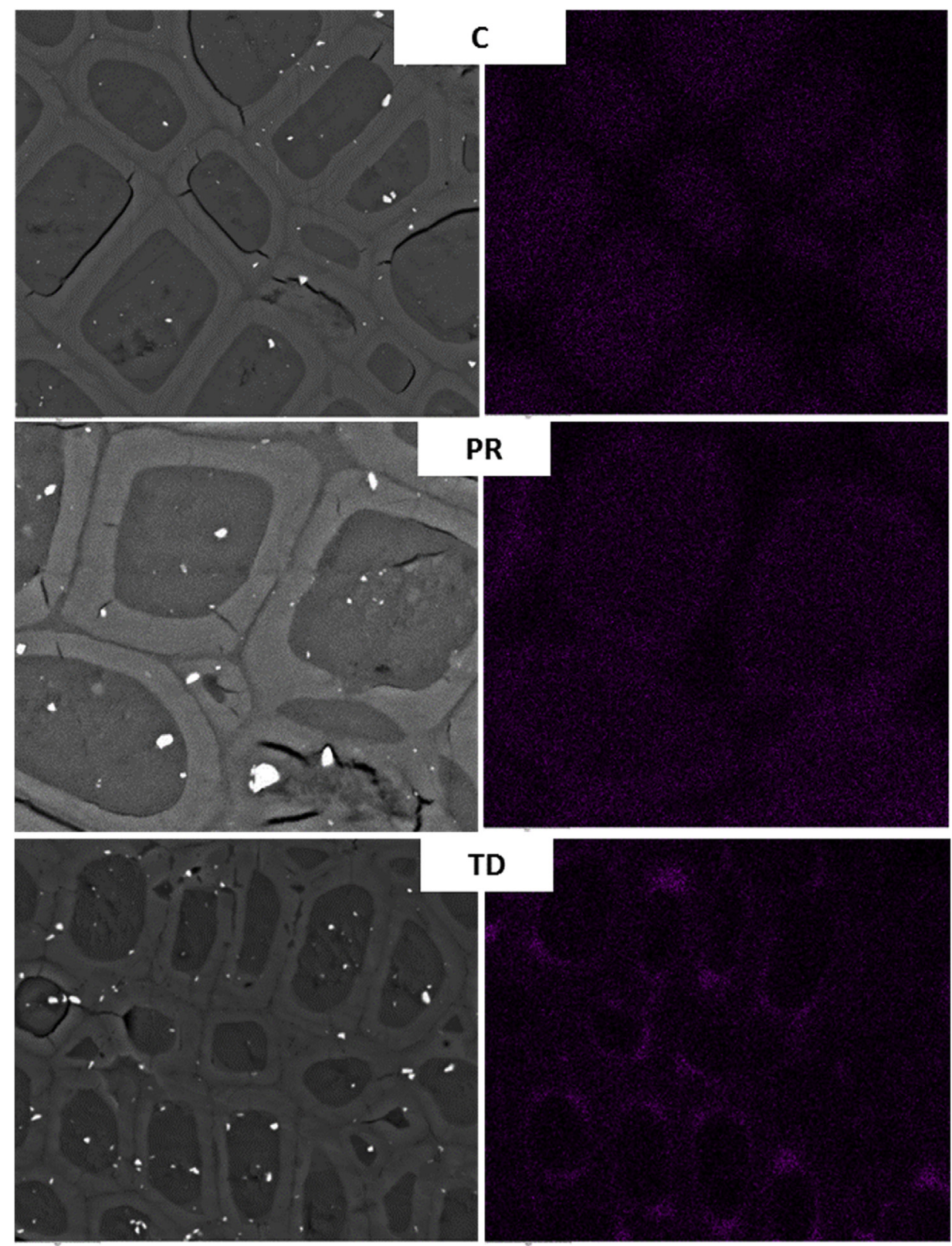

Fig. 6. SEM pictures of three woods (left) and corresponding phosphorus mapping (right). 

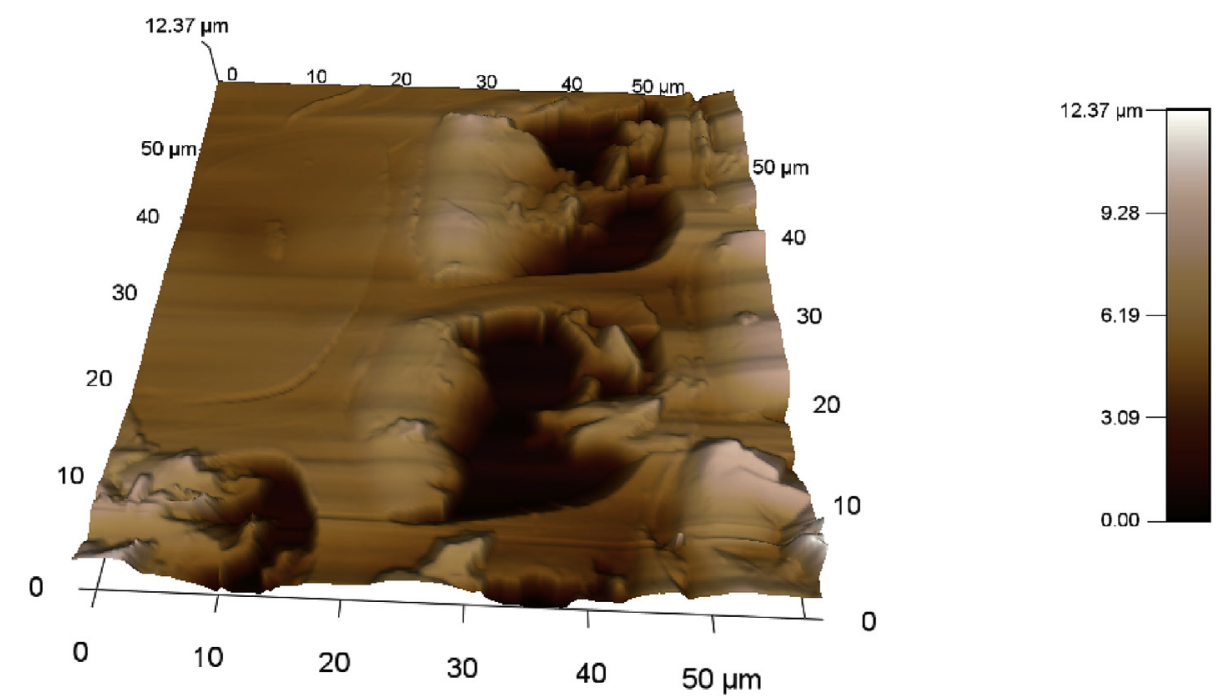

(a)
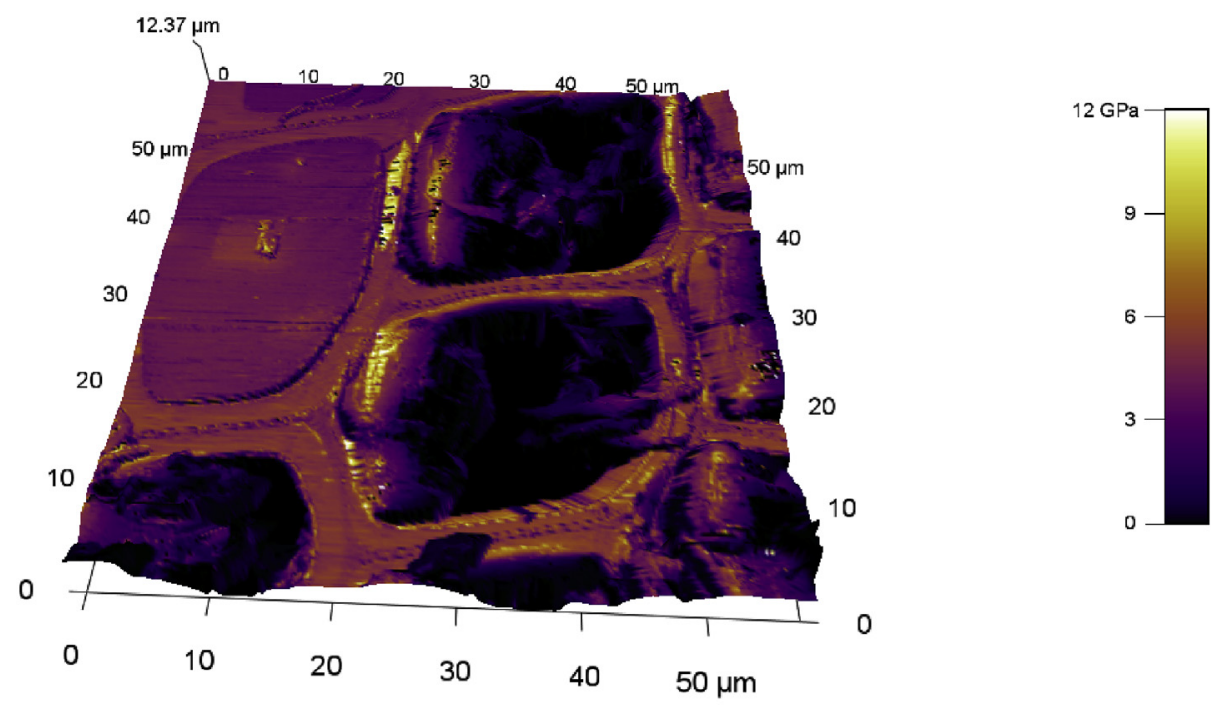

(b)

Fig. 7. AFM images of a pine sample with polyester resin: (a) topography, (b) elastic modulus.

were not monitored in the present study. Further investigations are needed to fully control the impregnation ratio during the process.

\subsubsection{Scanning electron microscopy}

Impregnation of woods by resins was investigated using scanning electron microscopy. Fig. 5 (left) shows the pine wood after modification by chlorinated resin (radial orientation). All pores at the surface are well clogged and the treatment appears homogeneous. It is also possible to observe some cracks which may come from the treatment process or the preparation of the samples for SEM observations. Observations were also made deeper in the sample (Fig. 5 right). At $1 \mathrm{~cm}$ from the surface (at the middle of $2 \mathrm{~cm}$-thick sample), many pores are still clogged. Nevertheless, some zones are totally resin-free (white arrow). Observations for all wood species impregnated with the neat resin and with the different FRs highlighted the heterogeneous character of the impregnation. At annual growth ring scale, absence of resin was noticed both in early and late wood. However, empty pores areas were more frequently detected in large cells (hardwood vessels and softwood tracheids in early wood) as illustrated in Fig. 5 (left).

Fig. 6 shows SEM pictures for three different woods modified with M1-containing resin. Impregnation ratio of these three woods is high (44-53\%). In all cases, resin filled perfectly the pores. For chestnut (C), phosphorus appears homogeneously dispersed in each pore. On the contrary, for TD species, phosphorus is highly concentrated in the cell walls. Phosphorus is more homogeneously dispersed for PR but may be slightly more concentrated in the cell walls. Such differences must be related to wood composition and structure and need further investigations.

\subsubsection{Atomic force microscopy (AFM)}

Fig. 7 shows AFM images of topography (a) and elastic modulus (b) for a pine sample with polyester resin. From topography, it is possible to observe that the wood surface is very rough, mainly in the porous areas where resin did not impregnate the sample. At the contrary, in the 


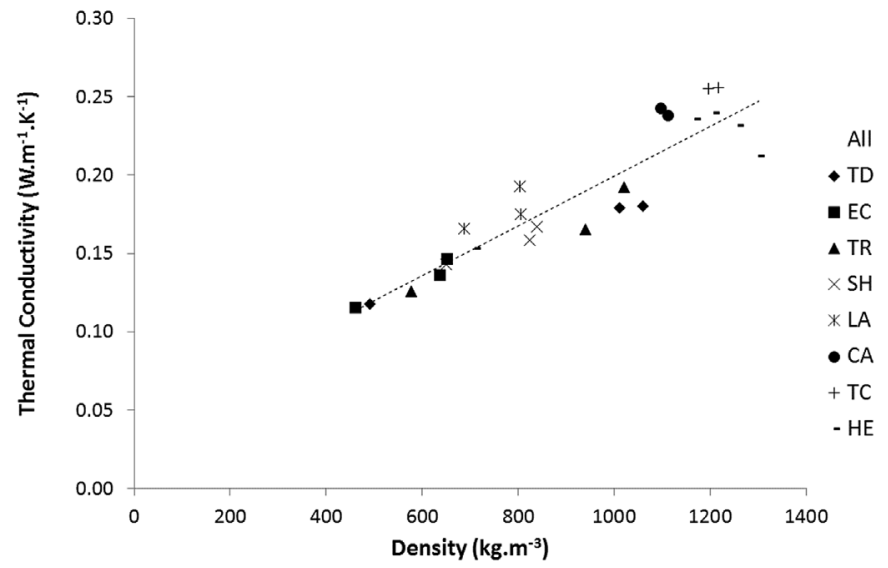

Fig. 8. Thermal conductivity versus density for woods and wood-plastic composites (small samples $7 \times 7 \times 1 \mathrm{~cm}^{3}$ ).

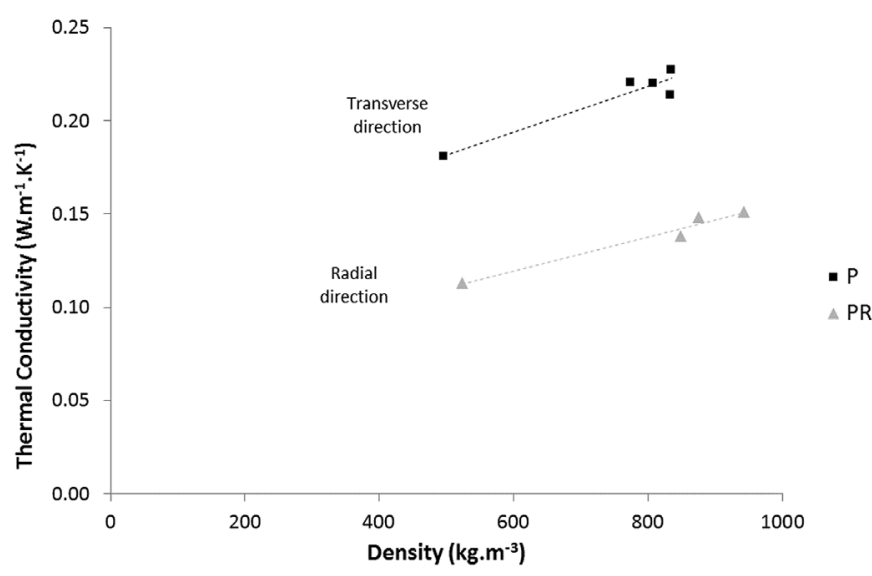

Fig. 9. Thermal conductivity versus density for woods and wood-plastic composites based on pine (radial and transverse orientation).

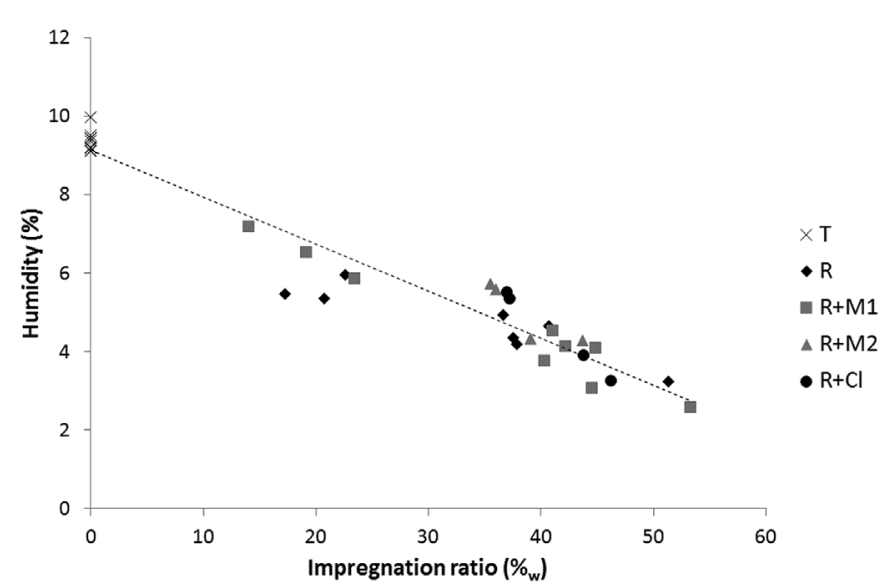

Fig. 10. Humidity versus impregnation ratio for all woods and wood-plastic composites.

impregnated areas, resin filled the pores homogeneously. This result is supported by cartography of the local elastic modulus that was found to be mostly homogeneous in the impregnated pore (shown in violet in Fig. 7 - b) and lower than that of the cell wall (in orange in Fig. 7 - a). Therefore, as expected, cell walls seem to be stiffer than the resin in pores. However, analyses here are interesting to evaluate the impregnation process and make qualitatively comparisons of local elastic moduli. Further AFM studies should be carried out to obtain quantitative results.

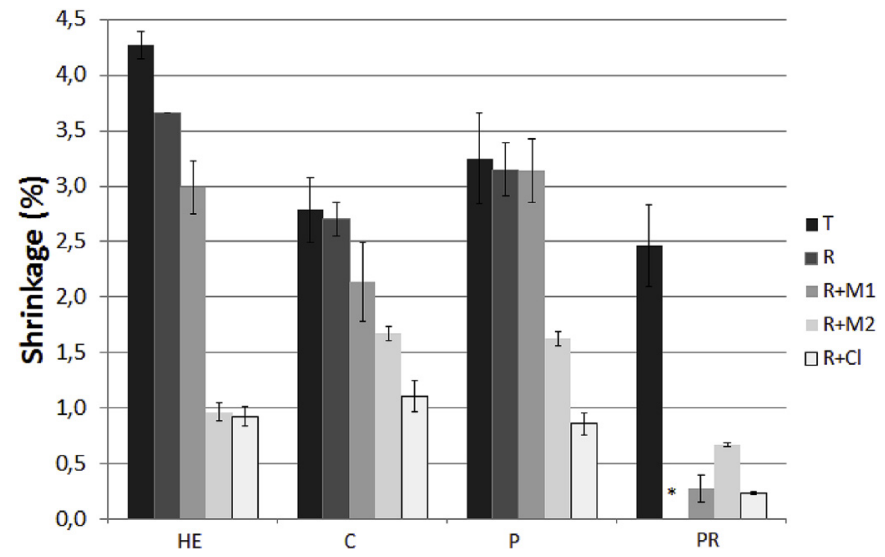

Fig. 11. Shrinkage (\%) for several wood samples modified or not with resins (* PR sample impregnated with $\mathrm{R}$ resin was not prepared).

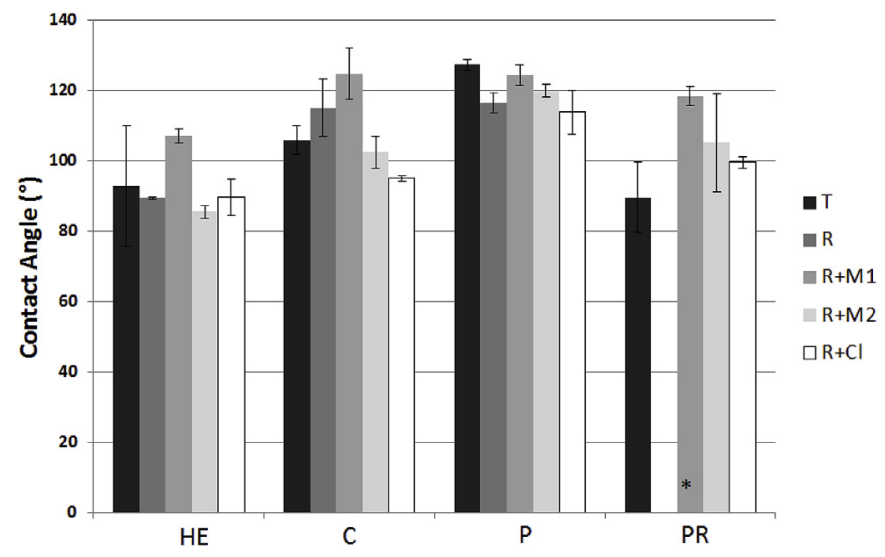

Fig. 12. Contact angle $\left({ }^{\circ}\right)$ with water for several wood samples modified or not with resins (* PR sample impregnated with $\mathrm{R}$ resin was not prepared).

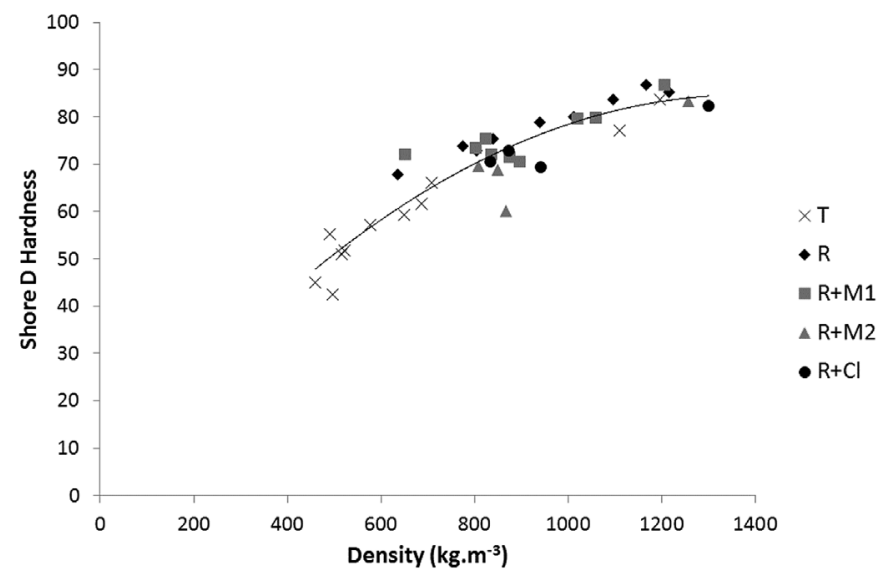

Fig. 13. Shore D hardness versus density for all woods and wood-plastic composites.

\subsection{Wood properties}

\subsubsection{Thermal conductivity}

Thermal conductivity is known to be reduced for porous materials. While pores are clogged by resin during impregnation, it is expected that thermal conductivity increases when impregnation ratio increases. Fig. 8 shows the thermal conductivity of woods (radial orientation) versus their density (before and after impregnation). As expected, thermal conductivity increases versus density. No significant difference 


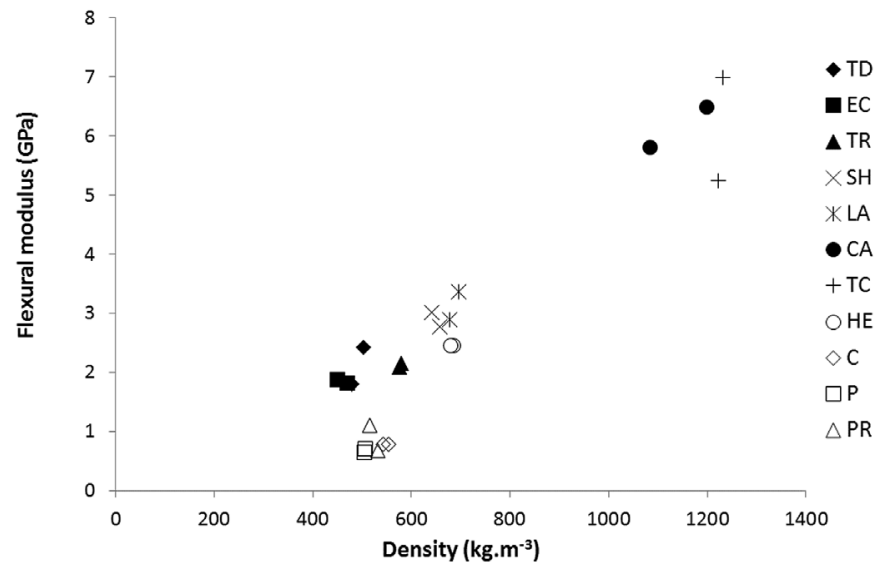

Fig. 14. Flexural modulus versus density for all studied woods.

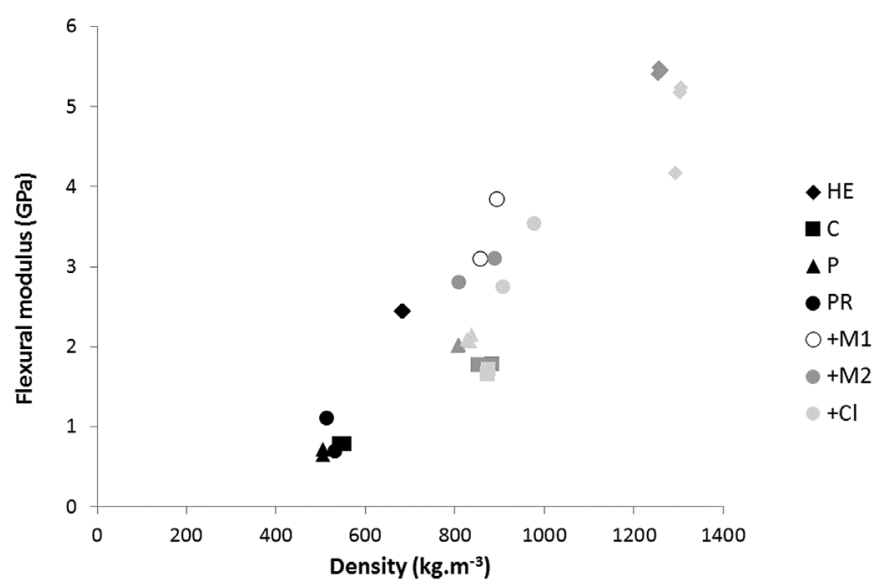

Fig. 15. Flexural modulus versus density for woods and wood-plastic composites based on pine, beech and chestnut species.

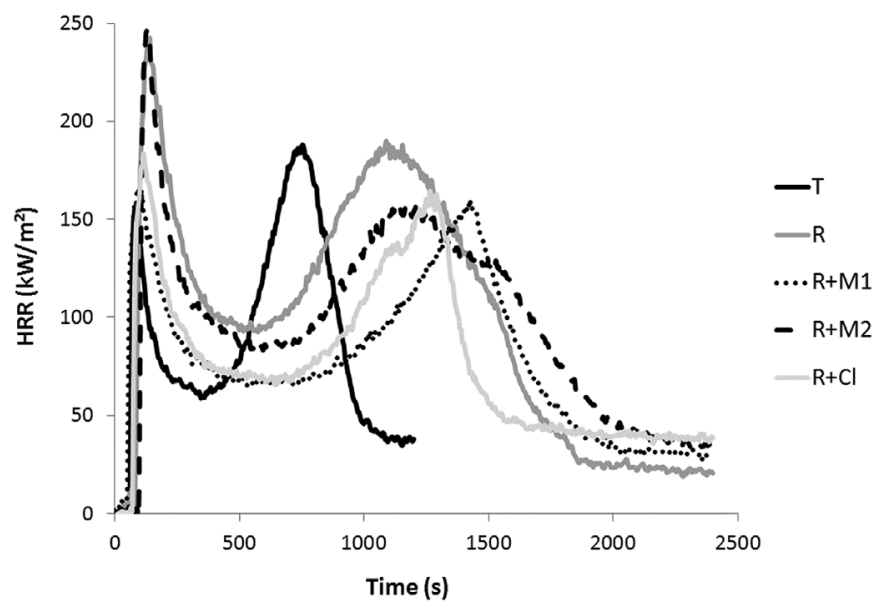

Fig. 16. Heat release rate curves in cone calorimeter tests for pine (transverse orientation) and pine-plastic composites.

is observed according to the wood species or the resin. Only the density (after impregnation) controls the thermal conductivity.

Nevertheless, sample orientation is also known to influence thermal conductivity while wood exhibits a highly anisotropic structure. Fig. 9 compares the thermal conductivity of P and PR woods. Remind that the wood species is the same, but the sample orientation is different. In both cases, thermal conductivity increases with density (impregnation ratio is similar for P and PR samples). Nevertheless, the thermal conductivity is significantly higher for transverse orientation (0.175- $0.225 \mathrm{~W} / \mathrm{m} . \mathrm{K}$ versus $0.1-0.15 \mathrm{~W} / \mathrm{m} . \mathrm{K}$ for radial orientation). Such discrepancy is well known in literature (Lagüela et al., 2015).

\subsubsection{Humidity}

While impregnation allows resins to clog the pores in wood structure, it is expected that the water content at $22{ }^{\circ} \mathrm{C} / 50 \% \mathrm{RH}$ decreases for wood-plastic composites. Fig. 10 shows that non modified woods (called T) exhibit a water content close to $9-10 \mathrm{wt} \%$, in good agreement with literature (Wood, 2001). The water content decreases linearly when impregnation ratio increases whichever the wood or the resin considered. When impregnation ratio is close to $50 \mathrm{wt} \%$, water content is only $3 \mathrm{wt} \%$. If the water content is calculated talking into account only the wood fraction, its value decrease more slowly with the impregnation ratio (around 7.5 and $6 \mathrm{wt} \%$ for impregnation ratio of 20 and $50 \mathrm{wt} \%$ respectively). Note also that these experiments give an insight on the water content at equilibrium but not on the kinectis of water diffusion.

\subsubsection{Shrinkage}

The dimensional stability of modified woods is improved. The shrinkage at $22{ }^{\circ} \mathrm{C}$ and $50 \%$ of relative humidity has been measured for beech, pine and chestnut samples (Fig. 11). All modified woods exhibit lower shrinkage than unmodified ones. Nevertheless, significant differences are observed depending on the resins, even for similar impregnation ratio. Especially, chlorinated resin and M2-containing resin allow reaching the lowest shrinkage values $(<1 \%$ for chlorinated resinmodified woods versus $2.5-4.3 \%$ for unmodified woods). The decrease in shrinkage is limited when impregnation is performed with non-flame retarded or M1-containing resins.

\subsubsection{Contact angle}

Fig. 12 shows results of contact angle measurements of water on wood-plastic composites. Contact angle initially ranges from 90 to $120^{\circ}$ depending on the wood (beech, chestnut and pine) and the sample orientation. After modification of wood, slight changes are observed but are not systematic. Note that the incorporation of M1 allows reaching the highest contact angles whichever the wood species. The highest improvement in hydrophobicity is obtained for pine (radial orientation): $+30^{\circ}$ with M1-containing resin.

\subsubsection{Mechanical properties}

Hardness can be used to measure the surface modification after a treatment on wood materials but little information about treated wood hardness is available in the literature (Salca and Hiziroglu, 2014). In this work, we measured the shore D hardness of the woods and the wood-plastic composites. Hardness values are plotted versus density in Fig. 13 for all wood-plastic composites. Hardness increases with density, i.e. depends on the wood and the impregnation ratio. No significant difference is observed according to the used resin. The increase in hardness is especially significant for the least dense samples. Above a density of $1000 \mathrm{~kg} / \mathrm{m}^{3}$, hardness increases marginally.

Samples stiffness was assessed using vibration analysis. Fig. 14 plots the flexural modulus versus the density for all unmodified woods. For most samples, flexural modulus ranges from $2 \mathrm{GPa}$ for $500 \mathrm{~kg} / \mathrm{m}^{3}$ to 6-7 GPa for $1200 \mathrm{~kg} / \mathrm{m}^{3}$. Nevertheless, C, P and PR seem to exhibit significantly lower modulus around $1 \mathrm{GPa}$ for a density close to $500-550 \mathrm{~kg} / \mathrm{m}^{3}$. This point needs further investigation.

Flexural modulus was also assessed for some wood-plastic composites based on beech, chestnut and pine species (Fig. 15). Flexural modulus increases when woods are impregnated and the increase is correlated to the density i.e. it depends on the wood species and the impregnation ratio. The increase in flexural modulus seems to be higher for PR and lower for $\mathrm{C}$ species. 

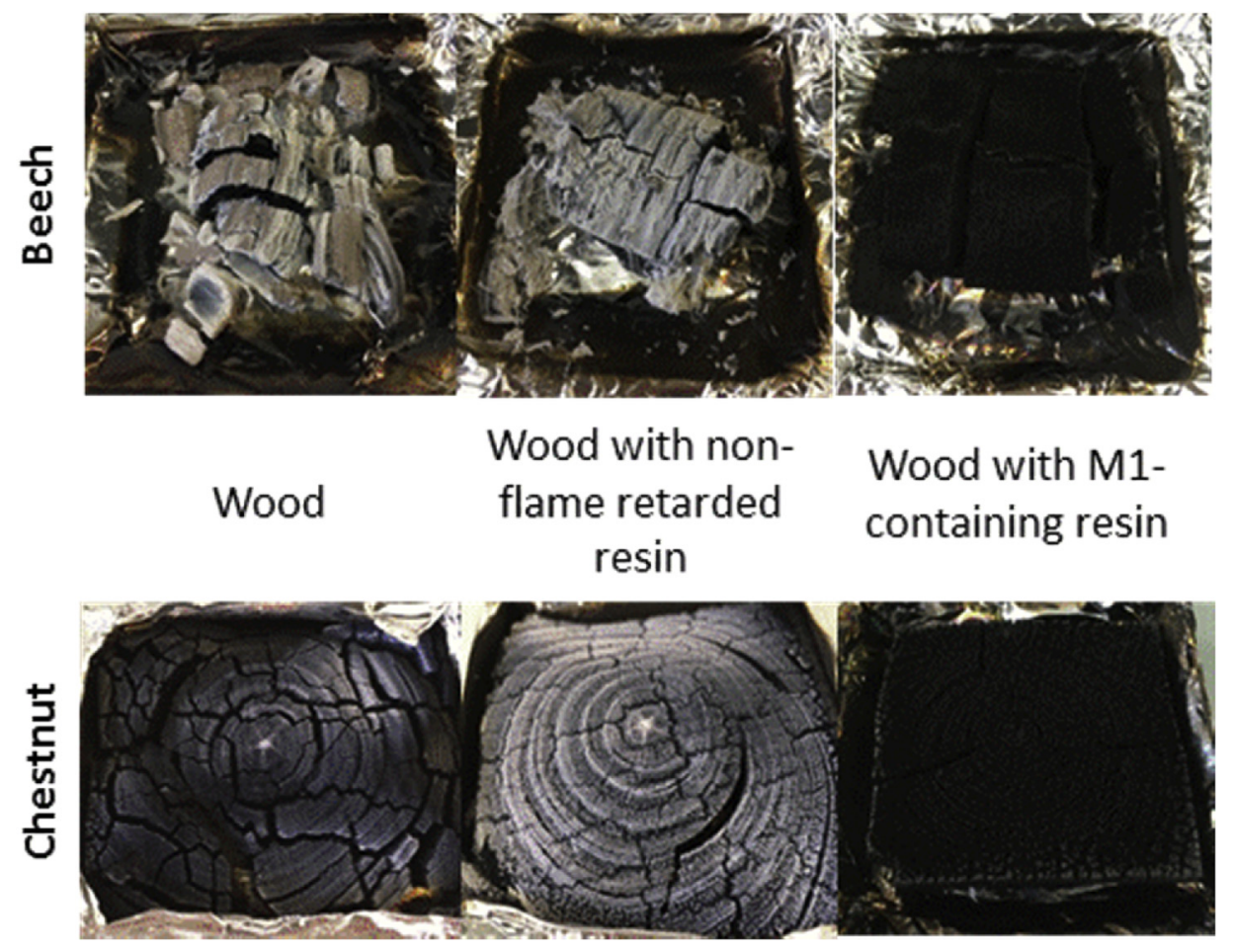

Fig. 17. Residues from cone calorimeter tests for some chestnut and beech-based materials.

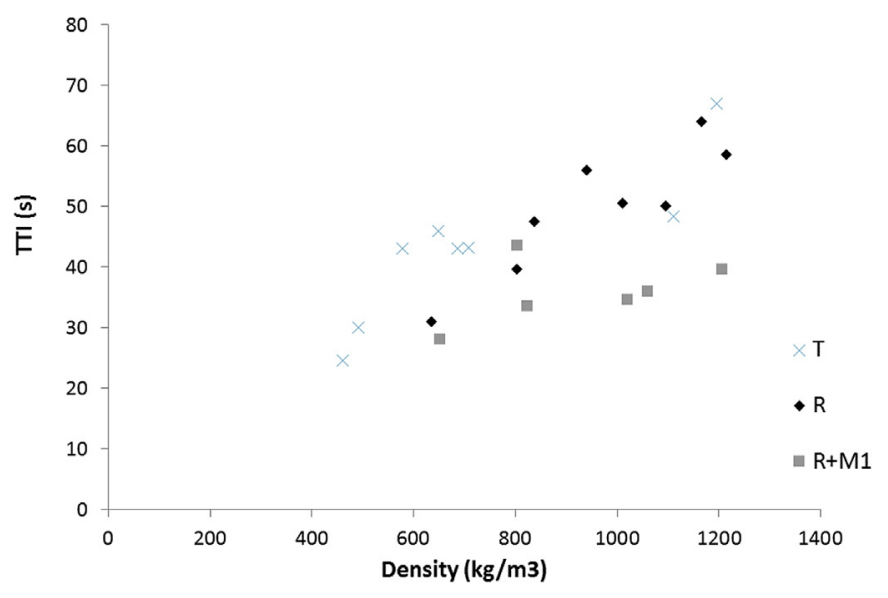

Fig. 18. Time-to-ignition versus density for woods and wood-plastic composites (small samples $7 \times 7 \times 1 \mathrm{~cm}^{3}$ ).

\subsubsection{Flammability}

Fire behavior of woods has already been investigated using cone calorimeter. As an example, flammability of the Mexican species tested in this study has been reported elsewhere (Haurie et al., 2019). Briefly, the heat release rate curves exhibit two peaks. The first one appears few seconds after ignition and the second one is related to the breakdown of the char layer. Effective heat of combustion is typical of many lignocellulosic materials ( $8-13 \mathrm{~kJ} / \mathrm{g}$ ). Charring is observed but the charring ability is difficult to compare due to thermo-oxidation at the end of the test. Most of properties, as time-to-ignition, peak of heat release rate, time-to-peaks and total heat release (when expressed in $\mathrm{MJ} / \mathrm{m}^{2}$ ) are obviously dependent on density.

The impregnation of woods by a resin greatly influences the flammability. Non-flame retarded resins strongly increase the flammability due to high decomposition rate and heat of combustion. Total heat release (in $\mathrm{MJ} / \mathrm{m}^{2}$ ) strongly increases when impregnation ratio increases. Nevertheless, the increase in density can positively influence

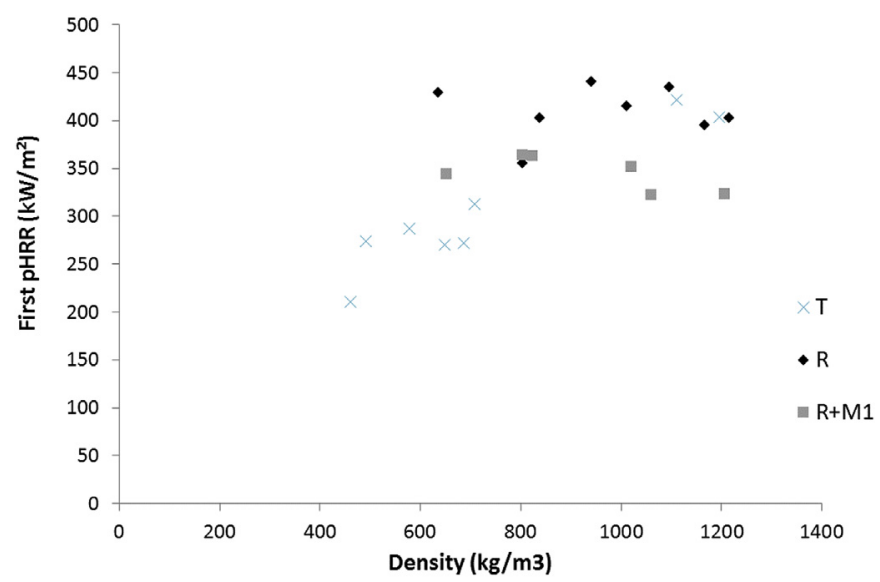

Fig. 19. First pHRR versus density for woods and wood-plastic composites (small samples $7 \times 7 \times 1 \mathrm{~cm}^{3}$ ).

some properties, as time-to-ignition due to thermal inertia. Finally when a flame retardant is added it also modifies the properties by limiting the flammability of the resin and/or wood, through char promotion or flame inhibition effects. Interactions between flame retardants and woods may also occur and depend on wood species.

In this study, we describe the main changes in flammability when the resins are incorporated into wood species, without focusing on some effects observed with specific woods. Typically, the incorporation of the different resins into woods leads to the changes illustrated in Fig. 16 (corresponding to pine). Resins do not modify significantly time-to-ignition. First pHRR is enhanced with non-flame retarded resin and moderated with other ones. The second peak of heat release rate is not necessarily reduced but delayed (due to thermal inertia). Total heat release (i.e. the area under the curve) is greatly enhanced.

Residues after cone calorimeter tests change significantly when flame-retarded resins are incorporated. Fig. 17 shows some pictures of various residues from wood materials based on beech and chestnut. Wood residues are cracked and little char is observed from the surface 


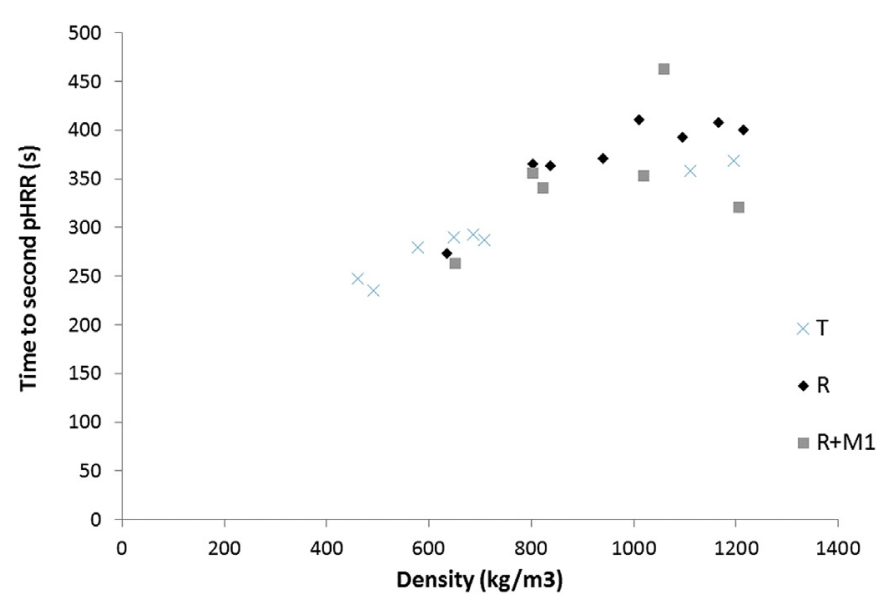

Fig. 20. Time to second pHRR versus density for woods and wood-plastic composites (small samples $7 \times 7 \times 1 \mathrm{~cm}^{3}$ ).

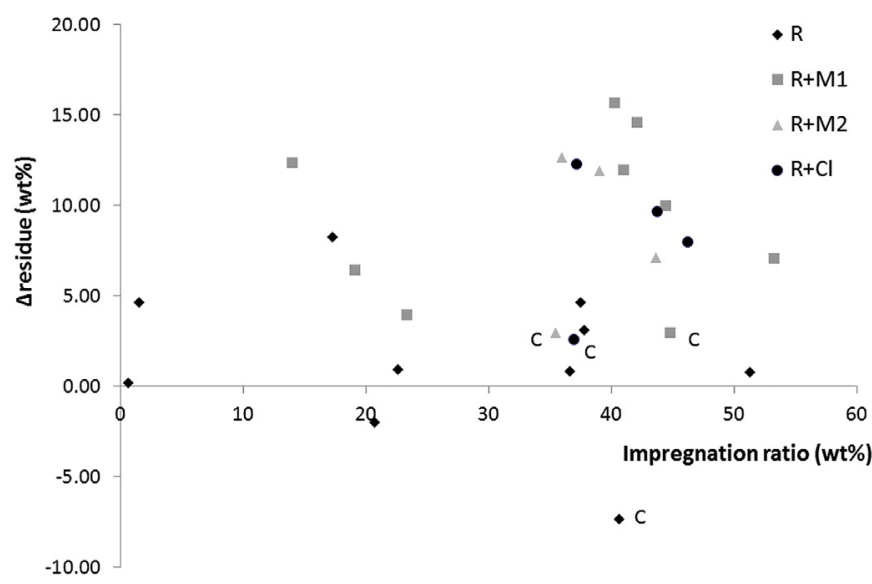

Fig. 21. Change in residue content versus impregnation ratio for all woodplastic composites.

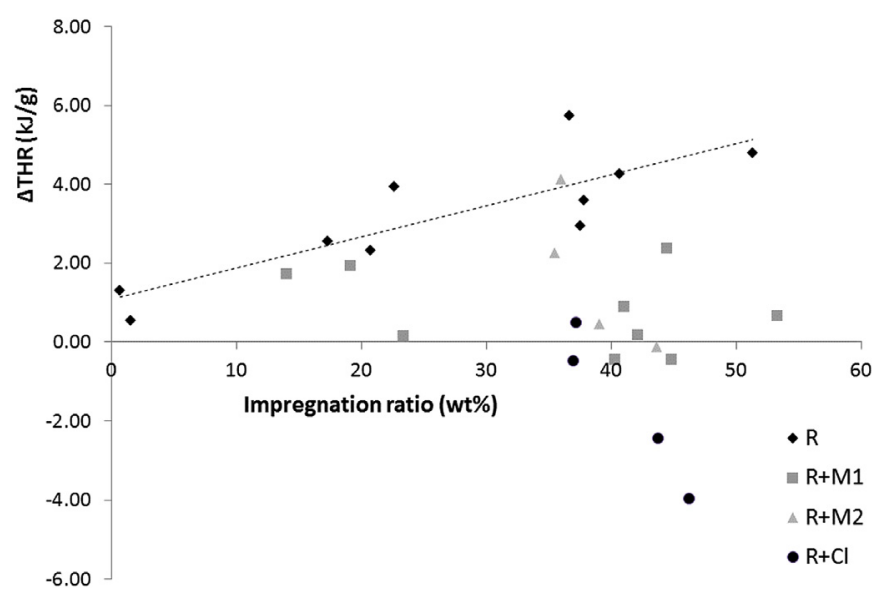

Fig. 22. Change in THR versus impregnation ratio for all wood-plastic composites.

color. The incorporation of non-flame retarded resin does not change greatly the aspect of the residues. Nevertheless the incorporation of phosphorus monomers leads to black residues indicative of the presence of char. It is well known that phosphorus enhances the char formation but also its thermo-oxidative stability. Probably the char formed from wood and wood modified with the non-flame retarded resin undergoes thermo-oxidation at the end of the cone calorimeter test. Flame-

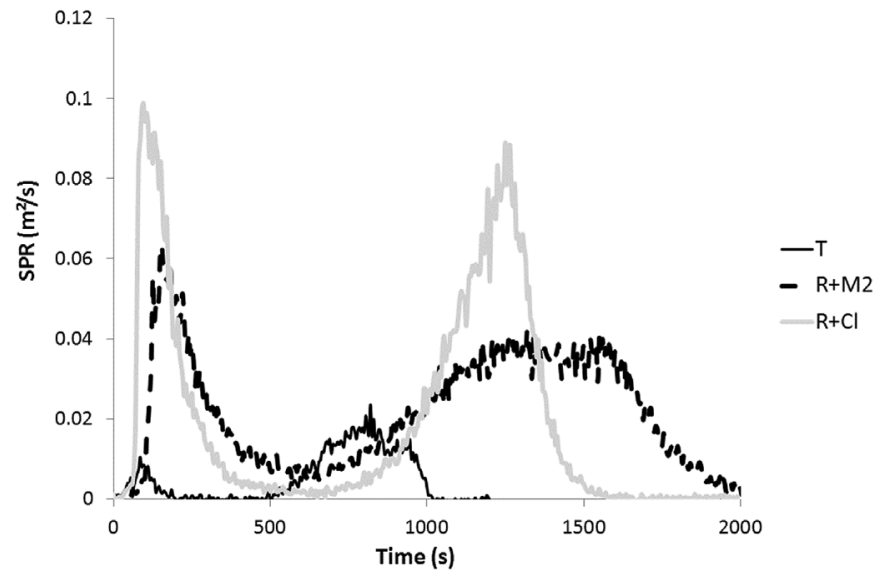

Fig. 23. Smoke production rate curves in cone calorimeter tests for pine (transverse orientation) and some pine-plastic composites.

retarded resins protect the char from such phenomenon. Note also that the beech-based residues are fully broken, even after modification. On the contrary, in the case of chestnut, the incorporation of resins, especially flame retarded ones, prevent the cracking to some extent.

While heat release rate also depends on the size of samples, we separately discuss the results for $7 \times 7 \times 1 \mathrm{~cm}^{3}$ and $10 \times 10 \times 2 \mathrm{~cm}^{3}$ samples. Moreover, depending on the properties, we have plotted the results versus the density or the impregnation ratio.

Time-to-ignition (TTI) is plotted versus density in Fig. 18 for $7 \times 7 \times 1 \mathrm{~cm}^{3}$ samples. Time-to-ignition depends on density (i.e. thermal inertia delays ignition from 25 to 70 s when density increases from 500 to $1200 \mathrm{~kg} / \mathrm{m}^{3}$ ). Non flame retarded resin does not affect the time-to-ignition. The presence of phosphorus (M1 compounds) promotes ignition. For similar densities, wood-plastic samples containing M1 exhibit lower TTI. Same conclusions can be drawn for $10 \times 10 \times 2$ $\mathrm{cm}^{3}$ samples (see Fig. S1 in supporting information). Nevertheless, TTI is higher with M2 and similar to the values obtained with the non-flame retarded resin. Intermediate values are observed for chlorinated resin. PR wood ignites early and then resins do not reduce its TTI.

First pHRR also depends on density at least for wood samples (see Fig. 19). Interestingly, the incorporation of resins increases its value, which becomes independent on density. The presence of M1 allows reducing the pHRR (from 400 to $450 \mathrm{~kW} / \mathrm{m}^{2}$ for non-flame retarded resin to around $350 \mathrm{~kW} / \mathrm{m}^{2}$ ). For larger samples, the pHRR is significantly lower and the influence of the resins seems to depend on the wood species (see Fig. S2 in supporting information).

The intensity of the second pHRR is mainly in the range $250-350 \mathrm{~kW} / \mathrm{m}^{2}$ for smaller samples and $130-200 \mathrm{~kW} / \mathrm{m}^{2}$ for larger ones. There is no clear tendency when resin is incorporated, even if M1 may decrease slightly this peak (see Figs. S3 and S4 in supporting information). On the contrary, this second PHRR is delayed when density increases and then when impregnation ratio of a resin is high. Nevertheless, there is no great difference between the resins: the time to second pHRR is mainly dependent on the density of the wood-plastic sample (Fig. 20 and Fig. S5 in supporting information). Of course, this second pHRR appears later for larger samples.

Gain in residue is plotted versus the impregnation ratio (Fig. 21). The incorporation of non-flame retarded resin does not modify greatly the residue content (compared to unmodified woods). Two exceptions are observed: residue content increases and decreases significantly respectively for LA and C species. Specific behavior has been already observed for LA (Haurie et al., 2019).

It can be also observed that flame retarded resins do not increase the char content of $\mathrm{C}$ species (increase is lower than $3 \mathrm{wt} \%$ compared to unmodified wood). For all other woods, M1, M2 and chlorinated resins enhance the char content. The increase reaches more than $15 \mathrm{wt} \%$ for 
M1 in bleech. While the intrinsic residue content of these resins is 17-21 wt\% (see Table 2), and the impregnation ratio is lower than $55 \mathrm{wt} \%$, such increase must be ascribed to some interactions with wood.

Finally the increase in THR (in $\mathrm{kJ} / \mathrm{g}$ - obviously THR in $\mathrm{kJ} / \mathrm{m}^{2}$ significantly increases in presence of resin) is plotted in Fig. 22. For samples containing the non-flame retarded resin, the change in THR depends on the impregnation ratio while the heat release from this resin is almost twice higher than the heat of combustion of woods. When phosphorus compounds are added, the char promotion reduces the total heat release (compared to non-flame retarded resin) even if the M1 and M2 resins also exhibit high heat release (see Table 2). The total heat release is almost the same as unmodified woods when impregnation ratio is high, except for $\mathrm{C}$, because the charring is limited, as discussed above.

Chlorinated resin is more efficient. Total heat release decreases even compared to unmodified woods. This can be ascribed to char promotion but also to the intrinsic low heat release of this resin. Flame inhibition effect of chlorinated compounds on combustion of gases released from wood pyrolysis can also be assumed.

Smoke production was also recorded for some samples. Fig. 23 shows the smoke production rate versus time curves for pine and pine materials modified with M2-based resin and chlorinated resin. Both resins increase strongly the smoke production as well as the smoke production rate peaks. Both resins exhibit similar smoke production but M2-based resin reduces the peaks of SPR to some extent in comparison to chlorinated resin. Nevertheless, it is clear that the enhancement of smoke release remains a major drawback of the incorporation of a resin into wood.

\section{Conclusion}

Wood-plastic composites were prepared by impregnation and radiation-curing of thermoset resins. In order to limit the negative impact of the resin on the flammability, phosphorus comonomers were added to the unsaturated polyester. Another flame retarded (chlorinated) resin was also studied. All resins were fully cured for a radiation dose comprised between 30 and $40 \mathrm{kGy}$.

Impregnation is incomplete and quite heterogeneous but impregnation ratio can reach around $50 \mathrm{wt} \%$. It depends on the density but also on the species of the wood. Most of the physical properties considered in that study are proved to be mainly related to the final density of the wood-plastic composites: hardness, stiffness, water content. Thermal conductivity depends on the density but also on the sample orientation (transverse versus radial orientation).

Flammability depends on the density and the incorporation of the non-flame retarded resin is highly detrimental. The incorporation of phosphorus allows mainly to promote charring and to keep the heat release close to the value measured for unmodified wood. The flame retardant performances of phosphorus-based resins remain lower than those obtained with the chlorinated resin. Several woods exhibit unexpected behaviors, as chestnut for which the char promotion is quite inefficient. Further investigations on such specific behaviors are needed.

The wood modification method proposed in this article allows improving some properties (for example mechanical properties) without enhancing the flammability, because the flame retardancy provided by phosphorus-based groups counterbalances the detrimental effect of unsaturated polyester resin. In order to improve the fire behavior compared to the unmodified wood itself, it will be needed to increase significantly the phosphorus content or to choose a low-flammable (high charring) resin.

\section{Acknowledgment}

The authors acknowledge the Ecole des Mines d'Alès for supporting the FERIA project (Prix André Lefebvre) and the MINECO (Spain) and FEDER for their financial support under the project BIA2017-88401-R.

\section{Appendix A. Supplementary data}

Supplementary data to this article can be found online at https:// doi.org/10.1016/j.radphyschem.2019.108547.

\section{References}

NF EN 1995-1-2, Eurocode 5 - Design of Timber Structures - Part 1-2 : General - Structural Fire Design.

Boryziak, S., 2010. A study of transcrystallinity in polypropylene in the presence of wood irradiated with gamma rays. J. Therm. Anal. Calorim. 101, 439-445.

Haurie, L., Giraldo, M., Lacasta, A.-M., Monton, J., Sonnier, R., 2019. Influence of different parameters in the fire behaviour of seven hardwood species. Fire Saf. J. 107, 193-201.

Hoorfar, M., Neumann, A.W., 2006. Recent progress in axisymmetric drop shape analysis (ADSA). Adv. Colloid Interface Sci. 121, 25-49.

Jimenez, M., Bellayer, S., Revel, B., Duquesne, S., Bourbigot, S., 2013. Comprehensive study of the influence of different aging scenarios on the fire protective behavior of an epoxy based intumescent coating. Ind. Eng. Chem. Res. 52, 729-743.

Lagüela, S., Bison, P., Peron, F., Romagnoni, P., 2015. Thermal conductivity measurements on wood materials with transient plane source technique. Thermochim. Acta 600, 45-51.

Le Moigne, N., Sonnier, R., El Hage, R., Rouif, S., 2017. Radiation-induced modifications in natural fibres and their biocomposites: opportunities for controlled physico-chemical modification pathways? Ind. Crops Prod. 109, 199-213.

Lowden, L.A., Hull, T.R., 2013. Flammability behaviour of wood and a review of the methods for its reduction. Fire Sci. Rev, 2, 4.

Mangin, R., Vahabi, H., Sonnier, R., Chivas-Joly, C., Lopez-Cuesta, J.-M., Cochez, M., 2018. Improving the resistance to hydrothermal ageing of flame-retarded PLA by incorporating miscible PMMA. Polym. Degrad. Stab. 155, 52-66.

Momoh, M., Horrocks, A.R., Eboatu, A.N., Kolawole, E.G., 1996. Flammability of tropical woods - I. Investigation of the burning parameters. Polym. Degrad. Stab. 54, 403-411.

Munnikendam, R.A., 1967. Conservation of waterlogged wood using radiation polymerization. Stud. Conserv. 12 (2), 70-75.

Neuhaus, S., Spencer, N.D., Padeste, C., 2012. Anisotropic wetting of microstructured surfaces as a function of surface chemistry. Appl. Mater. Interfaces 4 (1), 123-130.

Njankouo, J.M., Dotreppe, J.-C., Franssen, J.-M., 2004. Experimental study of the charring rate of tropical hardwoods. Fire Mater. 28, 15-24.

Njankouo, J.M., Dotreppe, J.-C., Franssen, J.-M., 2005. Fire resistance of timbers from tropical countries and comparison of experimental charring rates with various models. Constr. Build. Mater. 19, 376-386.

Salca, E.-A., Hiziroglu, S., 2014. Evaluation of hardness and surface quality of different wood species as function of heat treatment. Mater. Des. 416-423.

Shebani, A.N., van Reenen, A.J., Meincken, M., 2008. The effect of wood extractives on the thermal stability of different wood species. Thermochim. Acta 471, 43-50.

Tran, Q.K., Ramière, R., Ginier-Gillet, A., 1990. Impregnation with radiation-curing monomers and resins. In: Archaeological Wood, Properties, Chemistry and Preservation, Advances in Chemistry Series $N^{\circ} 225$. American Chemical Society, Washington DC.

Tran, K., Guinard, M., 2009. Stabilisation of dry archaeological wood having sulphur compounds by impregnation of radiation-curing unsaturated polyester resin. In: Straetkvern, K., Huisman, D.J. (Eds.), Proceedings of the 10th ICOM Group on Wet Archaeological Materials Conference, Amsterdam (2007), (Amersfoort).

Wood, I. Hartley, 2001. Moisture content, hygroscopicity, and sorption. In: Encyclopedia of Materials: Science and Technology, second ed. pp. 9668-9673. 